\title{
Pemindaian Kemampuan Institusi Pendidikan Teologi untuk Menghadapi Transformasi Digital di Indonesia
}

\author{
Aldrin Purnomo, ${ }^{1 *}$ Irfan F. Simanjuntak ${ }^{2}$, Joni M. P. Gultom ${ }^{3}$, Jan Lukas Lombok ${ }^{4}$ \\ 1,2,3,4Prodi Teologi, STT Real Batam \\ aldrin.cares@gmail.com
}

\begin{abstract}
The presence of industry 4.0 creates new challenges due to industry needs. The formation is inevitable, including theological educational institutions. Theological education institutions must transform towards the needs of industry 4.0 so that they can produce graduates who are able to adapt in the new industrial era environment. For this reason, a structured scanning process is needed and provides detailed explanations so that strategic digital transformation policies can be implemented efficiently and effectively. The scanning process is carried out using the management approach, leadership and expertise of the theological education institution. These three things are the main points of reference that will be processed quantitatively to provide appropriate empirical and qualitative data. This research resulted in a mapping pattern that was applied to scan the ability of theological institutions to be prepared to face thenew industrial era.
\end{abstract}

Keywords: industry 4.0, theological education, digital transformation

\begin{abstract}
Abstrak
Kehadiran industri 4.0 membentuk tantangan baru akibat kebutuhan industri. Pembentukan tersebut tidak terelakkan termasuk institusi pendidikan teologi. Institusi pendidikan teologi harus melakukan transformasi ke arah kebutuhan industri 4.0 sehingga dapat menetak lulusan yang mampu beradaptasi di lingkungan era industri yang baru. Untuk itu diperlukan sebuah proses pemindaian yang terstruktur dan memberikan penjelasan yang detail agar kebijakan transformasi digital strategis dapat diterapkan dengan efisien dan efektif. Proses pemindaian dilakukan dengan pendekatan manajemen, kepemimpinan serta keahlian institusi pendidikan teologi tersebut. Ketiga hal ini merupakan pokok acuan yang akan diproses secara kuantitatif untuk memberikan data empiris dan kualitatif yang tepat. Penelitian ini menghasilkan sebuah pola pemetaan yang diterapkan untuk memindai kemampuan institusi teologi terhadap kesigapan menghadapi era industri yang baru.

Kata kunci: industri 4.0, pendidikan teologi, transformasi digital
\end{abstract}




\section{PENDAHULUAN}

Perkembangan industri yang mulai memasuki tahap revolusi ke empat atau yang dikenal sebagai Industry 4.0, secara perlahan mulai mempengaruhi kehidupan manusia. Berbagai persiapan untuk memasuki era industri ini telah dimulai secara progresif dan serius karena akan memberikan dampak yang positif bagi dunia Industry. Pemanfaatan cyber-physical-system sebagai tulang punggung perubahan industri ini dengan kombinasi perangkat lunak, multi sensor, prosesor kecepatan tinggi serta dukungan teknologi jaringan dan telekomunikasi akan memberikan nilai tinggi bagi proses manufakturing yang baru. ${ }^{1}$ Inovasi yang dilakukan oleh dunia Manufacturing ini memiliki kecepatan yang belum pernah ada sebelumnya dengan persaingan yang bisa muncul tiba-tiba dengan menggunakan teknologi baru. Perubahan yang bisa digambarkan sebagai "perubahan dalam semalam" akan membuat industri yang tidak memiliki respons yang cepat dipastikan akan mendapatkan masa depan yang suram. ${ }^{2} \mathrm{Hal}$ ini persis seperti yang dijelaskan oleh Fransiskus Irwan dkk, the world has continuously experienced the ongoing process of change, which is always preceded and guided by science, also known as the human cognitive domain. ${ }^{3}$

Pengaruh penerapan Industri 4.0 memang belum terasa secara signifikan namun persiapan untuk menuju perubahan ini sudah mulai di terapkan khususnya di beberapa bidang manufaktur. Kementerian Perindustrian Republik Indonesia telah memulai menganalisis posisi Indonesia di dalam mempersiapkan Indonesia memasuki era Industri 4.0. Tujuannya adalah: 1)Meningkatkan kontribusi net ekspor dari $0.8 \%$ di tahun 2018 menjadi 10\%; 2) Meningkatkan efisiensi produktivitas menjadi 2x lipat; 3) Meningkatkan pertumbuhan pembiayaan pengembangan dan penelitian menjadi 2\% dari GDP dibandingkan 0,3\% di tahun 2016. Kementerian Perindustrian telah meneliti 10 sektor bidang usaha yang akan menjadi target dari penerapan Industri 4.0. Indonesia ingin memanfaatkan Bonus Demografi pada tahun 2030-2040. Pada periode tersebut, penduduk

\footnotetext{
${ }^{1}$ Mohd Aiman Kamarul Bahrin et al., "Industry 4.0: A Review on Industrial Automation and Robotic," Jurnal Teknologi, 2016.

2 John Barcus, "Accelerating Innovation at the Speed of Industry 4.0," Manufacturing Leadership Council, last modified 2018, accessed February 17, 2021, https://www.manufacturingleadershipcouncil.com/2018/08/03/accelerating-innovation-atthe-speed-of-industry-4-0/.

${ }^{3}$ Fransiskus Irwan Widjaja, Fredy Simanjuntak, and Noh Ibrahim Boiliu, "Repositioning Mission in Postmodern Culture," in Proceedings of the 1st International Conference on Education, Society, Economy, Humanity and Environment (ICESHE 2019) (Paris, France: Atlantis Press, 2020), https://www.atlantis-press.com/article/125936174.
} 
usia produktif diprediksi mencapai 64 persen dari total jumlah penduduk yang diproyeksikan sebesar 297 juta jiwa. Namun Indonesia harus mempersiapkan angkatan kerja ini agar menjadi angkatan kerja yang produktif yang sesuai dengan pola industri baru yang diterapkan melalui literasi yang tepat. ${ }^{4}$

Salah satu persyaratan yang diperlukan untuk mendukung penerapan Industri 4.0 di Indonesia adalah sumber daya manusia dengan kemampuan baru. Dunia Industri 4.0 menuntut kemampuan hard skill dan soft skill untuk menangani proses kerja di dalam struktur teknologi industri yang pintar, fleksibel dan saling berhubungan satu dengan yang lainnya melalui network system yang sangat cepat. Lingkungan ini biasa dikenal dengan Smart Factory (pabrik pintar) dimana manusia dituntut untuk bisa menangani berbagai masalah yang kompleks berpikir kritis, koordinasi yang baik dengan orang lain serta kreativitas. ${ }^{5}$ Banyak penelitian menunjukkan bahwa literasi digital akan menjadi kemampuan utama bagi angkatan kerja di masa depan yang diartikan sebagai kemampuan untuk melakukan pekerjaan melalui sistem digital. Literasi digital juga diartikan sebagai kemampuan mulai dari keterampilan teknis (seperti yang digunakan dalam pengkodean), hingga kewarganegaraan digital, hingga kemampuan untuk mengidentifikasi berita palsu". Dalam praksis pemanfaatan teknologi bukan hanya literasi digital yang diperlukan tetapi juga ketangkasan digital (digital dexterity) yang dimaknai sebagai ${ }^{1}$ kemampuan dan keinginan untuk menggunakan teknologi yang ada dan yang muncul untuk hasil bisnis yang lebih baik ${ }^{1} .{ }^{6}$ Literasi dan ketangkasan digital dibentuk oleh dunia pendidikan yang juga harus bertransformasi secara digital untuk menghadapi perubahan ini. Transformasi digital dunia pendidikan diperlukan untuk mempersiapkan tenaga kerja yang siap pakai yang memiliki kemampuan literasi dan ketangkasan digital yang memadai. Hal ini secara langsung akan menuntut setiap institusi pendidikan harus memiliki kapabilitas dan kapasitas untuk pembentukan sumber daya ini.

${ }^{4}$ Rina Indiastuti, "Pengembangan Ekosistem Inovasi Dan Kurikulum Edukasi Untuk Mendukung Revolusi Teknologi Manufaktur 4.0," in Industrial Summit: Implementasi Industri 4.0 Dalam Rangka Transformasi Lanskap Industri Nasional Menuju Top 10 Ekonomi Dunia 2030 (Jakarta: Direktorat Jenderal Pembelajaran dan Kemahasiswaan Kementerian Riset, Teknologi, dan Pendidikan Tinggi, 2018).

${ }^{5}$ Andrea Benesova et al., "Requirements for Education 4.0 and Study Programs within Industry 4.0," in Proceedings of the International Conference on Industrial Engineering and Operations Management, 2019.

${ }^{6}$ Rania Nafea and Esra Kilicarslan Toplu, "Future of Education in Industry 4.0: Educational Digitization - A Canadian Case Study," in Business Management and Communication Perspectives in Industry 4.0, 2020. 
Melihat implikasi yang ditimbulkan, institusi pendidikan yang terlibat dalam persiapan ini bukan hanya dari institusi pendidikan teknik ataupun eksakta, namun juga institusi pendidikan sosial budaya. Dampak dari penerapan Industri 4.0 bukan saja hanya pada dunia industri semata tetapi juga pada pola kehidupan manusia. Sehingga kemampuan untuk menangani dampak sosial budaya penerapan Industri 4.0 akan ditangani dengan memahami pola transformasi yang terjadi di dalam masyarakat. Klaus Schwab, pendiri dan ketua World Economic Forum (Forum Ekonomi Dunia), berpendapat bahwa transformasi digital di dalam industri 4.0 tidak hanya akan mengubah apa yang dilakukan manusia tetapi juga siapa manusia itu. Hal ini juga akan memengaruhi identitas, rasa privasi, gagasan tentang kepemilikan, pola pemakaian, waktu yang dicurahkan untuk bekerja dan bersantai, bagaimana mengembangkan karier, mengembangkan keterampilan, bertemu orang-orang dan membina hubungan satu dengan yang lainnya. ${ }^{7}$

Pendidikan teologi adalah salah satu bidang pendidikan yang sangat penting untuk mempersiapkan para pelayan Tuhan di dunia yang sedang bertransformasi menuju Industri 4.0. Program pendidikan yang diselenggarakan oleh institusi pendidikan teologi harus mengarah kepada kemampuan yang diperlukan saat para lulusan melakukan pelayanan di dunia yang sedang berubah. Institusi pendidikan teologi bertanggung jawab untuk mempersiapkan para lulusan yang mampu membentuk karakter manusia agar tidak berbudaya secara individualistis dan memiliki kemampuan menghargai sesama dengan menilai manusia berdasarkan fungsinya. Produk institusi pendidikan teologi mampu mengembangkan karakter fungsional multidimensi berupa pengenalan nilai-nilai kemanusiaan, penghayatan, pengembangan potensi, dan mengingat tujuan hidup setiap orang percaya yaitu memuliakan Tuhan. ${ }^{8}$

Diskusi yang dilakukan dengan beberapa narasumber dari sejumlah pimpinan institusi teologi di Indonesia, dapat disimpulkan bahwa kesulitan yang dihadapi oleh banyak institusi teologi saat ini adalah: 1) Kegagalan memahami atas perubahan yang akan terjadi; 2) Tidak memiliki strategi institusi yang berkesinambungan agar mudah beradaptasi dengan perubahanperubahan di depan yang akan terus terjadi; 3) Ketidakmampuan sumber

\footnotetext{
${ }^{7}$ Wim A. Dreyer, "Being Church in the Era of 'Homo Digitalis,"” Verbum et Ecclesia (2019).

${ }^{8}$ Heriyanto et al., "Character Education in the Era of Industrial Revolution 4.0 and Its Relevance to the High School Learning Transformation Process," Utopia y Praxis Latinoamericana (2019).
} 
daya yang diperlukan untuk melakukan transformasi di dalam lembaga. ${ }^{9}$ Setiap institusi memiliki karakter manajemen dan strategi yang berbedabeda. Namun pengharapan untuk mempersiapkan diri agar dapat melakukan transformasi sangat tinggi. Namun setiap institusi memiliki keterbatasan dan kelebihan yang beragam. Untuk itu diperlukan suatu cara untuk pemindaian yang dapat melihat apakah sebuah institusi teologi mampu untuk menghadapi perubahan yang akan terjadi. Pemindaian ini juga akan langsung memberikan informasi langkah-langkah apa yang harus disiapkan agar institusi teologi dapat melihat posisi institusi terhadap tantangan perubahan ini, mempersiapkan langkah-langkah strategis yang tepat, mempersiapkan sumber daya yang tepat dan menetapkan strategi yang berkesinambungan untuk menghadapi perubahan-perubahan yang terus terjadi dengan cepat. Informasi yang dihasilkan harus bersifat komprehensif agar langkah-langkah yang disiapkan memiliki efektivitas dan efisiensi yang baik serta didukung oleh determinasi seluruh pemangku kebijakan di dalam institusi.

\section{METODE}

Peralatan penelitian yang dipakai untuk melakukan pemindaian kemampuan institusi pendidikan teologi di Indonesia saat ini adalah menggunakan metode penelitian kualitatif analitik dengan melakukan 2 tipe analisis yaitu : 1) Penelitian dan pengumpulan data melalui studi literatur dan referensi yang menyangkut persiapan institusi pendidikan menghadapi era industri yang baru; 2) Pengumpulan data dari beberapa institusi pendidikan teologi di Indonesia melalui kuesioner untuk melihat kemampuan yang dimiliki masing-masing institusi dalam mempersiapkan diri menjelang penerapan Industri 4.0.

Penelitian dan pengumpulan data hasil studi literatur digunakan untuk mencari pendekatan inteligensia digital (digital quotient) yang sesuai untuk institusi pendidikan teologi. Berbagai metode pengembangan kedua hal ini didasarkan oleh beberapa dasar penelitian sebelumnya yaitu : 1) Kerangka yang dikembangkan oleh suatu organisasi atau pemerintah; 2) Adanya dokumen tertulis yang relatif lengkap dan dapat diakses secara terbuka; 3) Mencakup aspek atau bidang kompetensi tertentu. ${ }^{10}$ Sebagai langkah selanjutnya dari penelitian ini, diperlukan sebuah aktivitas

\footnotetext{
${ }^{9}$ Wawancara dilakukan dengan melakukan diskusi langsung dengan para nara sumber yang aktif sebagai pimpinan, pengampu maupun mahasiswa pascasarjana di beberapa institusi pendidikan teologi di Indonesia. Pertanyaan yang diajukan menyangkut pemahaman Industry 4.0 termasuk penerapan serta tantangan yang dihadapi. Informasi juga dilakukan saat menjawab pertanyaan dan dalam diskusi sebagai pembicara di beberapa institusi teologi baik berupa diskusi langsung dengan para pimpinan maupun dalam bentuk kuliah umum langsung dengan mahasiswa baik tingkat sarjana, magister maupun doktoral

${ }^{10}$ Pupu Saeful Rahmat, "Penelitian Kualitatif," Journal Equilibrium, 2009.
} 
pengumpulan data yang akan diproses secara kuantitatif untuk mengukur secara empiris nilai kesigapan institusi tersebut.

\section{HASIL DAN PEMBAHASAN}

\section{Transformasi sebagai sebuah panggilan}

Misi Allah bagi umat manusia adalah sebuah kesinambungan sejak jaman Perjanjian lama hingga jaman Perjanjian Baru. Baik misi yang dilakukan Allah melalu bangsa Israel maupun misi yang diteruskan oleh gereja di jaman Perjanjian Baru, agar konektivitas Allah degan manusia tidak terputus. Konektivitas diperlukan karena Allah menciptakan manusia untuk diri-Nya. Dalam hal ini bangsa Israel maupun gereja memiliki mandat untuk memperkenalkan Allah kepada manusia yang belum percaya untuk datang kepada-Nya dan mengenal-Nya sebagai pencipta mereka. ${ }^{11}$ Amanat Agung di dalam Matius 28:16-20 adalah fondasi penting yang tidak akan berubah sampai kapan pun. Kontrak pekerjaan ini hanya akan berakhir saat Yesus datang kembali ke dalam dunia. ${ }^{12}$ Missio Dei yang secara harfiah berarti "pengiriman Tuhan" atau "misi Tuhan" telah lama dipikirkan secara strategis semenjak tahun 1932 saat Konferensi Misionaris di Brandenburg oleh Karl Barth. Hal ini diulangi kembali pada tahun 1952 di dalam Konferensi Misionaris yang sama di kota Willingen sebagai sebuah penyebab dari Allah yang Tritunggal yang diekspresikan sebagai Bapa mengutus Anak, Bapa dan Anak mengutus Roh Kudus dan Bapa, Anak dan Roh Kudus mengutus gereja ke dalam dunia. Hasil akhirnya adalah rekonsiliasi yang sempurna dan Tuhan akan memimpin semua. ${ }^{13}$

Alkitab juga dengan tegas menekankan transformasi yang berkelanjutan (continuous transformation). Dalam Roma 12:2 Paulus menulis: "Janganlah kamu menjadi serupa dengan dunia ini, tetapi berubahlah oleh pembaharuan budimu, sehingga kamu dapat membedakan manakah kehendak Allah: apa yang baik, yang berkenan kepada Allah dan yang sempurna." Ayat ini menekankan makna transformasi yang harus dilakukan secara berkesinambungan oleh setiap manusia. Kata Yunani yang mendasari ayat ini adalah metamorphoo (I1cTaI1opcpów) yang menekankan kepada perubahan (change) dan perubahan rupa (transfiguration). Hal ini

\footnotetext{
${ }^{11}$ Fransiskus Irwan Widjaja, Misiologi Antara Teori Fakta Dan Pengalaman (Yogyakarta: Penerbit Andi, 2018).

${ }^{12}$ Aldrin Purnomo and Yudhy Sanjaya, "Tantangan Dan Strategi Gereja Menjalankan Misi Allah Dalam Menghadapi Penerapan Industri 4.0 Di Indonesia," Diegesis 3, no. 2 (2020).

${ }^{13}$ Kirk Franklin and Nelus Niemandt, "Polycentrism in the Missio Dei," HTS Teologiese Studies / Theological Studies (2016).
} 
menunjukkan kepada perubahan akal budi (mindset), intelektualisasi, dan pengertian. Dengan demikian transformasi adalah sebuah kebenaran Alkitab bagi orang percaya sebagai sebuah perintah untuk dilakukan dan harus dialami oleh setiap orang percaya untuk semakin mengerti kehendak Tuhan, yang baik dan berkenan kepada-Nya dan yang membuat semakin sempurna. ${ }^{14}$

Institusi pendidikan teologi pun harus memahami bahwa transformasi yang dilakukan harus di dalam sebuah kerangka pekerjaan Allah yang sempurna. Transformasi tidak terlepas dari setiap langkah kerja pekerjaan Allah bagi setiap utusan ataupun rasul-rasulnya dan misionaris di dunia ini. Perubahan teknologi tidak lepas dari konteks penyebaran Injil kepada banyak orang. Mulai dari pola para murid yang menyampaikannya dengan kata-kata, kemudian Paulus yang menggunakan surat-suratnya, para penginjil yang menggunakan transkrip dan para reformis yang menggunakan mesin cetak dan seterusnya, menjadi bukti bahwa teknologi membawa transformasi di dalam pekerjaan ini. ${ }^{15}$

\section{Konsep pemindaian yang dilakukan}

Proses pemindaian menggunakan pola penilaian survei terhadap penerapan konsep Leadership Managing Tools. Konsep ini menerapkan kluster fungsi manajemen, kepemimpinan dan keahlian secara terpisah namun saling mendukung. ${ }^{16}$ Dengan konsep ini maka mudah untuk melihat faktor-faktor yang berpengaruh akan lebih mudah dipahami. Ketiga kluster ini akan bersinergi untuk memberikan nilai mengenai kemampuan institusi pendidikan terhadap kemampuan menghadap penerapan Industri 4.0. Kluster

${ }^{14}$ Rehobot Ministry, "Kebenaran Yang Mentransformasi," Rehobot Ministry, last modified 2019, accessed March 8, 2021, https://www.rehobot.org/beranda_renungan/kebenaran-yang-mentransformasi/.

${ }^{15}$ Katherine G. Schmid, "Digital Inculturation," in Missio Dei in a Digital Age, ed. Jonas Kurlberg and Peter M. Phillips (London: SCM Press, 2020).

${ }^{16}$ Infineon Technologies Batam, Manager Communication Handbook: Leading and Managing People (Batam, 2019). 


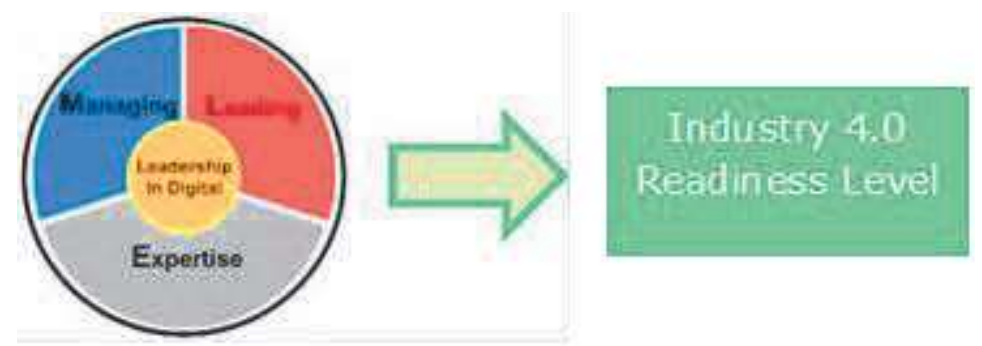

Gambar 1. Bagan Dasar Konsep Pemindaian

\section{Manajemen yang berbasis digital}

Di era Industri 4.0 setiap manajemen sebuah lembaga dituntut memiliki kemampuan baru melalu pengembangan inovasi digital dan teknologi. Inovasi digital dan teknologi akan menjadi bagian yang esensial bagi manajemen lembaga hari ini yang mempengaruhi kemampuan pengumpulan data, kinerja aset lembaga serta fleksibilitas dalam pengambilan keputusan. ${ }^{17}$ Inovasi ini akan menumbuhkan sebuah budaya digital di dalam manajemen. Budaya digital adalah penerapan proses digital dengan segala implementasinya termasuk aspek-aspek yang mempengaruhi kehidupan kita terhadap digital itu sendiri. Batasannya tidak hanya hingga sampai kepada penggunaan gadget dan media sosial, tetapi juga mempengaruhi pola budaya, cara kerja dan bagaimana berhubungan dengan lebih efektif. ${ }^{18}$

Kemampuan digital sumber daya yang dimiliki oleh manajemen juga memainkan peranan penting. Kegagalan banyak institusi saat ini adalah tidak memperhatikan peningkatan kemampuan digital sumber daya yang dimiliki. Bagi institusi pendidikan, kemampuan sumber daya ini akan memberikan poin penting karena institusi tersebut tidak akan bergerak secara digital jika sumber dayanya tidak memiliki kemampuan yang cukup untuk beroperasi secara digital. Kegagalan tersebut meliputi sedikit pengalaman berinteraksi dengan dunia digital, tidak memiliki peranti digital yang cukup, kemampuan yang rendah untuk bekerja di dunia digital dan kurang kesempatan untuk bekerja di dunia digital. ${ }^{19}$

\footnotetext{
${ }^{17}$ Krešimir Buntak, Matija Kovačić, and Ivana Martinčević, "Knowledge Management in Digital Era," in Conference: Advances in Business-Related Scientific Research Conference (Ljubljana, 2019).

${ }^{18}$ Laila Mohebi, "Educational Leadership and Digital Culture," SSRN Electronic Journal (2019).

${ }^{19}$ Ibid. 6
} 


\section{Pengembangan kepemimpinan berbasis Digital}

Arnold mengutarakan kepemimpinan digital diperlukan oleh seluruh institusi termasuk pimpinannya karena merupakan hal tersebut adalah pola pikir yang strategis yang akan mengangkat institusi ke jenjang berikutnya. Struktur berpikir ini akan melibatkan seluruh perangkat institusi yang ada baik proses belajar, pola komunikasi, lingkungan belajar yang inovatif dan penggunaan pola belajar yang profesional. ${ }^{20}$ Secara definisi, Arnold mengatakan bahwa kepemimpinan digital diperlukan sebagai pola pikir yang strategis dengan memanfaatkan sumber daya yang ada untuk peningkatan lebih lanjut tetapi mampu beradaptasi jika terjadi sebuah perubahan. Dengan demikian pola pikir ini sangat diperlukan oleh semua lembaga pendidikan dan sosial untuk mengembangkan dirinya lebih inovatif dan profesional. ${ }^{21}$

Strategi mempersiapkan kepemimpinan di masa mendatang harus dilakukan semenjak dini. Generasi yang sekarang memimpin dianggap tidak akan memiliki kemampuan yang efektif yang sesuai dengan pola kepemimpinan di masa mendatang. Berdasarkan penelitian yang dilakukan oleh seorang kolumnis majalah Forbes, terdapat lima hal yang bisa menjadi landasan menyangkut perubahan strategi ini yaitu fleksibilitas waktu kerja, fleksibilitas tempat kerja, Piranti komunikasi yang mudah dibawa dan digunakan, pembaharuan sistem teknologi secara berkala dan tetap terhubung antara setiap individu di dalam institusi. ${ }^{22}$

\section{Keahlian yang diperlukan di era Industri 4.0}

Kementerian Riset dan Pendidikan Tinggi Republik Indonesia sangat menekankan program kebijakan pengembangan kurikulum yang mengarah kepada peningkatan akses, relevansi, dan mutu pendidikan Tinggi di Indonesia yang menghasilkan SDM yang berkualitas di lapangan kerja yang menerapkan Industri 4.0. Pengembangan kurikulum tersebut diarahkan kepada: 1) Peningkatan Ko dan Ekstra Kurikuler; 2) Pendidikan Umum; 3) Kemampuan kognitif dan inovasi; 4) Pembelajaran sepanjang hayat; dan 5) Pengembangan literasi baru berupa literasi Data, literasi teknologi dan literasi manusia. ${ }^{23}$ Pengembangan literasi baru inilah yang menjadi titik

\footnotetext{
${ }^{20}$ Maik Arnold, "Leading Digital Change - Management of Hybridity and Change in Education and Social Service Institutions," Gemeinschaften in Neuen Medien 2020 Dresden (Dresden, 2020).

${ }^{21}$ Ibid.

${ }^{22}$ Purnomo and Sanjaya, "Tantangan Dan Strategi Gereja Menjalankan Misi Allah Dalam Menghadapi Penerapan Industri 4.0 Di Indonesia."

${ }^{23}$ Indiastuti, "Pengembangan Ekosistem Inovasi Dan Kurikulum Edukasi Untuk Mendukung Revolusi Teknologi Manufaktur 4.0."
} 
penting di dalam mempersiapkan mahasiswa untuk memiliki kemampuan baru yang diperlukan di era Industri 4.0.

Literasi Data adalah sebuah kemampuan yang sangat penting saat ini di dalam melakukan semua transaksi digital. Smolnikova bahkan menganggap literasi data sebagai bagian penting dari kepentingan bisnis yang meliputi kepentingan ekonomi, keamanan pribadi dan penggunaan data yang efektif yang di akomodasi dalam sebuah Big Data. ${ }^{24}{ }^{25}$ Menurut Ridsdale et al, literasi data adalah sebuah kemampuan untuk mengumpulkan, mengelola, mengevaluasi, dan menerapkan data secara kritis. ${ }^{26}$ Bagi institusi pendidikan literasi data harus dilatih agar mahasiswa mengerti pentingnya data yang akurat agar dapat mendorong inovasi dan menetapkan langkahlangkah penelitian selanjutnya. ${ }^{27}$ Langkah-langkah penelitian harus didukung oleh suatu kemampuan proses pengumpulan data yang baik hingga pengolahannya agar menjadi suatu kesimpulan untuk tindakan perbaikan. ${ }^{28}$ Untuk itu diperlukan kualitas data penelitian yang lengkap, akurat, konsisten, waktu yang tepat, unik (spesifik) dan memenuhi standar. Jace Ann menyatakan bahwa kemampuan mengumpulkan data yang berkualitas harus menjadi sebuah disiplin yang terstruktur di setiap organisasi penelitian. Kualitas data yang buruk adalah salah satu penyebab dari kegagalan inteligensia digital. ${ }^{29}$

Di dalam beberapa dekade penggunaan komputer, laptop, tablet dan telepon genggam pintar telah berubah menjadi alat yang paling diperlukan. Perkembangan teknologi informasi dan komunikasi melaju sangat cepat dan mempengaruhi struktur proses pembelajaran bagi seluruh pemangku kepentingan di dunia pendidikan. ${ }^{30}$ Menurut Paul Gilster dalam bukunya Digital Literacy, Literasi digital adalah sebuah kompetensi untuk memahami

${ }^{24}$ Marketa Smolnikova, "Next Step: Data Literacy Measurement" (Prague: University of Economics, W. Churchill Sq. 4, 2021).

${ }^{25}$ Big data adalah sebuah bidang yang berisi kumpulan proses dari berbagai macam data baik yang teratur maupun yang tidak dengan kompleksitas yang berbeda-beda. Big data adalah salah satu terobosan teknologi data yang menjadi salah satu pendukung di dalam ekosistem Industri 4.0. Lihat Wikipedia :

https://translate.google.com/translate? $\mathrm{u}=\mathrm{https}$ ://en.wikipedia.org/wiki/Big data\&hl=id\&sl=e $\underline{\mathrm{n} \& \mathrm{tl}=\mathrm{id} \& \mathrm{client}=\mathrm{sr}} \mathrm{p} \& \mathrm{prev}=\mathrm{search}$

${ }^{26}$ Chantel Ridsdale et al., "Strategies and Best Practices for Data Literacy

Education," Knowledge Synthesis Report (2015).

${ }^{27}$ Ibid. 5

${ }^{28}$ Smolnikova, "Next Step: Data Literacy Measurement."

${ }^{29}$ Jace An, 77 Building Blocks of Digital Transformation: Simply Explained, First Edit. (United States: Story Tree FDC, 2019).

${ }^{30}$ Krishnan Umachandran et al., "Designing Learning-Skills towards Industry 4.0," World Journal on Educational Technology: Current Issues (2019). 
semua informasi dalam berbagai format yang disajikan melalui media komputer. ${ }^{31}$ Kemampuan ini termasuk melakukan tugas secara efektif di lingkungan digital, keterampilan kognitif, motorik, sosiologis dan emosional yang kompleks yang dibutuhkan pengguna untuk berfungsi secara efektif di lingkungan digital. ${ }^{32}$

Kemampuan membangun manusia adalah suatu keahlian penting yang diperlukan di era Industry 4.0. Manusia adalah aset dalam setiap lembaga dan tanggung jawab lembaga untuk membangun aset tersebut untuk mengembangkan semua potensi baik keterampilan, kesehatan, pendidikan dan yang lainnya. ${ }^{33}$ Di dalam dunia teologi, maka skala kemampuan yang tepat adalah mempraktikkan teologi penggembalaan atau teologi pastoral dan semua turunannya. Teologi penggembalaan adalah domain yang tepat di dalam dunia teologi karena bersifat sebagai bentuk interaksi langsung dengan objek di dalam domain teologi yaitu manusia. Harianto menekankan bahwa di era globalisasi ini kemampuan menangani manusia (jemaat) semakin kompleks dan berkaitan satu dengan yang lainnya. Untuk itu diperlukan sebuah kemampuan dalam konteks teologi pastoral bagi seorang pelayan agar tetap melayani manusia (jemaat) untuk terus berkomitmen hidup di dalam Tuhan. ${ }^{34}$ Peter Wongso juga menekankan bahwa kemampuan memimpin umat dalam konteks penggembalaan adalah suatu kemampuan yang harus dimiliki oleh setiap hamba Tuhan. Istilah yang digunakan adalah sebuah keahlian dalam Ilmu Kepemimpinan Penggembalaan (Pastoral Leadership). ${ }^{35}$

\section{Kemampuan minimum yang diperlukan oleh institusi}

Kemampuan sebuah institusi untuk melihat kemampuan dirinya di dalam menghadapi kedatangan era industri yang baru bisa dilihat dari nilai kematangan digital yang dihasilkan dari survei yang dilakukan. Beberapa lembaga penelitian memiliki pola perhitungan yang berbeda. Di dalam penelitian ini digunakan skala yang dipakai oleh Mc Kinsey dan Digital

\footnotetext{
${ }^{31}$ Paul Gilster, Digital Literacy (New York: Willey, 1997).

${ }^{32}$ Eliana Gallardo-Echenique et al., "Digital Competence in the Knowledge Society," MERLOT Journal of Online Learning and Teaching (JOLT) 11, no. 1 (2018): 116 , https://www.researchgate.net/publication/273945449 Digital Competence in the Knowle dge Society.

${ }^{33}$ Emmanuel Flores, Xun Xu, and Yuqian Lu, "Human Capital 4.0: A Workforce Competence Typology for Industry 4.0," Journal of Manufacturing Technology Management (2020).

${ }^{34}$ Harianto GP, Teologi Pastoral (Yogyakarta: Penerbit Andi, 2020).

${ }^{35}$ Peter Wongso, Theologia Penggembalaan (Malang: Literatur SAAT, 1983).
} 
Quotient yang juga diterapkan oleh banyak perusahaan besar di dunia. Pola perhitungan memang berbeda-beda, namun Mc Kinsey dengan pola Digital Quotient ini menerapkan skor 33 sebagai batas antara kemampuan di bawah rata-rata dengan kemampuan di atas rata-rata sebuah institusi. ${ }^{36}$ Di bawah ini adalah hasil penelitian yang dilakukan oleh Mc Kinsey terhadap 150 perusahaan besar di dunia.

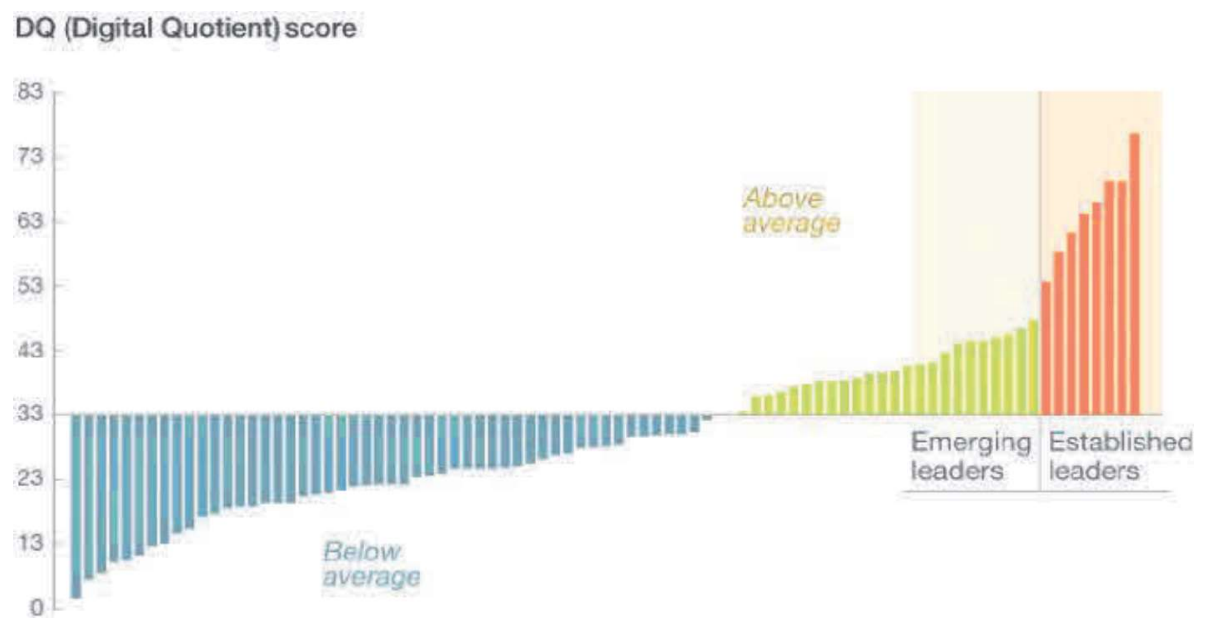

Gambar 2. Hasil Penilaian Kesiapan Digital oleh Mc Kinsey

\section{Model pemindaian dengan metode kuantitatif.}

Pendekatan pemindaian didesain untuk dilakukan kepada kemampuan inteligensia digital institusi tersebut. Pola yang dilakukan adalah dengan melakukan survei terhadap komponen-komponen sumber daya yang diperlukan. Didi Sudrajat menjelaskan bahwa penelitian survei sendiri merupakan sebuah metode penelitian deskriptif dengan mengumpulkan data pada sebuah titik tertentu dengan maksud melihat kondisi yang ada, identifikasi standar untuk perbandingan dengan kondisi yang ada serta menentukan hubungan peristiwa yang ada. ${ }^{37}$ Pola yang akan dilakukan adalah dengan melalui survei terhadap tiga kelompok sesuai Leadership Managing Tools dibagi dalam beberapa kategori yang menyangkut keahlian (expertise skill), kemampuan manajemen (managing skill) dan

${ }^{36}$ Tanguy Catlin, Jay Scanlan, and Paul Willmott, Raising Your Digital Quotient, 2015, https://www.mckinsey.com/business-functions/strategy-and-corporate-finance/ourinsights/raising-your-digital-quotient.

${ }^{37}$ Didi Sudrajat, Metode Penelitian Pendidikan Dengan Pendekatan Kuantitaif (Solo: Indo Pustaka Sinergis, 2016). 
kepemimpinan (leadership skill). Setiap kategori memiliki sub kategori yang menjadi pokok pemindaian. Target pemindaian adalah komponen yang terdapat di dalam institusi pendidikan yaitu: 1) Manajemen institusi pendidikan yang diwakili oleh salah satu unsur pimpinan institusi. 2) Kurikulum yang dipersiapkan untuk dipakai dalam proses belajar dan mengajar dan 3) Pengajar atau pengampu yang mengajar di institusi tersebut. Hasil dari survei akan memberikan gambaran mengenai kondisi institusi pendidikan teologi diperhadapkan dengan kebutuhan di era industri 4.0 yang relevan sesuai dengan fungsinya.

Dalam membangun pola pemindaian, maka seluruh unsur fungsi di manajemen, kepemimpinan dan keahlian dipakai dengan melihat hal tersebut secara detail. Setiap fungsi tersebut dibagi lagi ke dalam sub-fungsinya untuk mendapatkan hasil penilaian. Setiap sub-fungsi akan dihubungkan dengan responden target yang tepat agar mendapatkan data yang sesuai dengan kompetensinya. Keterhubungan ini nantinya akan diolah secara kuantitatif dan mendapatkan nilai yang tepat untuk mengukur kesigapan sebuah institusi teologi dalam menghadapi Industri 4.0. Pola pengumpulan data akan menggunakan survei dengan menerapkan skala Likert dengan nilai 1 sampai dengan 5. Setiap pernyataan memiliki 5 poin, dari skala Setuju dan Tidak Setuju. Masing-masing skor sub-fungsi dijumlahkan untuk menghasilkan skor total bagi responden. ${ }^{38}$

\section{Sub-unsur di dalam proses pemindaian}

Penentuan Sub Pokok dilakukan sesuai dengan teori yang mendasari proses pemindaian ini. Pembagiannya adalah sebagai berikut

a. Fungsi Manajemen. Fungsi Manajemen terbagi atas tiga subfungsi yaitu:

a.1. Sistem Manajemen Digital, yang akan memeriksa apakah institusi tersebut memiliki sebuah sistem manajemen yang menggunakan digital sebagai proses utama.

a.2. Sistem Pembelajaran Digital, untuk memeriksa apakah pola belajar mengajar sudah mempergunakan sarana digital yang memadai.

a.3. Manajemen Digital Sumber Daya, untuk memeriksa apakah semua sumber daya yang dimiliki oleh institusi memiliki budaya dan kemampuan untuk bekerja di dalam sebuah lingkungan ekosistem digital

b. Fungsi Kepemimpinan. Fungsi Kepemimpinan terbagi atas dua sub fungsi yaitu:

\footnotetext{
${ }^{38}$ Hardani, Metoda Penelitian Kuantitatif Dan Kualitatif (Yogyakarta: Penerbit
} Pustaka Ilmu, 2020). 
b.1. Program Kepemimpinan Muda, untuk memeriksa apakah institusi memiliki program untuk mencetak tenaga-tenaga manajemen dan pengajar muda untuk kepentingan kepemimpinan di masa mendatang

b.2. Kepemimpinan Berbasis Digital, untuk memeriksa setiap kebijakan yang diambil dan kecepatan penyesuaian penentuan kebijakan yang disesuaikan dengan kebutuhan untuk kemajuan institusi

c. Fungsi Keahlian. Fungsi Keahlian terbagi atas 3 sub fungsi yaitu:

c.1. Literasi Penelitian dengan Data, untuk memeriksa apakah institusi menetapkan suatu persyaratan bagai setiap penelitian untuk selalu berbasis kepada data yang akurat serta memberikan bimbingan yang tepat untuk pengumpulan data yang tepat.

c.2. Literasi Teknologi, untuk melihat porsi yang di tetapkan di dalam kurikulum untuk membina sebuah kemampuan digital yang tepat bagi setiap mahasiswa termasuk di dalamnya kemampuan bahasa Inggris yang baik.

c.3. Literasi Allah dan manusia, untuk memeriksa porsi bimbingan Teologi Pastoral dan segala turunannya yang bersifat human relationship capability (kemampuan berkoneksi dengan orang lain) di dalam kerangka sebagai seorang calon pelayan Tuhan

Di dalam gambar 3 dapat dilihat skema pemindaian yang akan dilakukan. Tanda panah di dalam gambar tersebut menunjukkan keterhubungan antara sub-fungsi yang akan diperiksa dengan target respondennya.

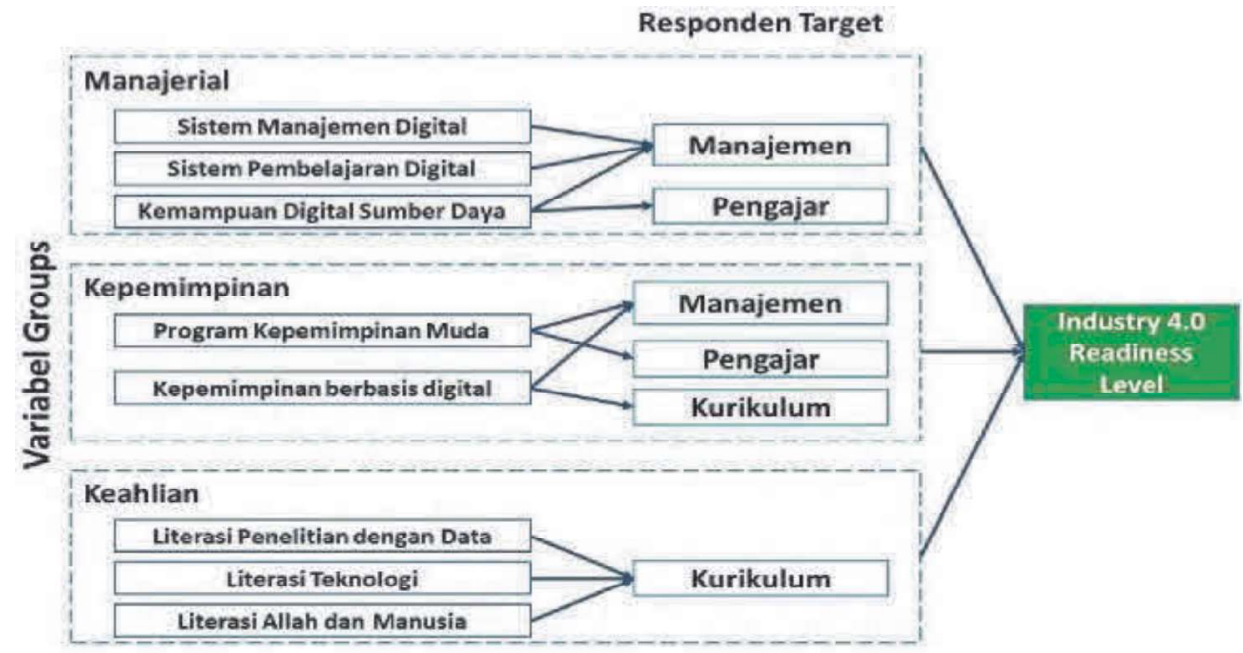

Gambar 3. Bagan Detail Konsep Pemindaian 


\section{KESIMPULAN}

Mempersiapkan institusi pendidikan teologi dalam menghadapi kedatangan era industri yang baru tidak dapat dihindari. Setiap institusi wajib mempersiapkan dirinya sejak dini agar memiliki kemampuan untuk membentuk lulusan yang berorientasi pada ladang pelayanan yang sudah bertransformasi di era industri yang baru. Diperlukan keputusan yang strategis agar tidak terjadi keterlambatan di dalam pemenuhan kebutuhan pasar di dalam dunia pelayanan baik di dalam gereja maupun di dalam masyarakat secara luas. Pemindaian semenjak dini akan memberikan gamparan yang luas terhadap setiap institusi untuk melakukan kegiatan peningkatan (improvement action) di sektor manajemen, kepemimpinan maupun keahlian. Peningkatan kemampuan yang tepat akan memberikan nilai kesigapan yang lebih tinggi. Seluruh pemangku kebijakan akan memiliki sebuah gambaran dan mengeluarkan keputusan yang strategis untuk melakukan investasi awal sebagai langkah menuju perubahan yang berkesinambungan.

\section{KEPUSTAKAAN}

An, Jace. 77 Building Blocks of Digital Transformation: Simply Explained. First Edit. United States: Story Tree FDC, 2019.

Arnold, Maik. "Leading Digital Change - Management of Hybridity and Change in Education and Social Service Institutions." Gemeinschaften in Neuen Medien 2020 Dresden. Dresden, 2020.

Bahrin, Mohd Aiman Kamarul, Mohd Fauzi Othman, Nor Hayati Nor Azli, and Muhamad Farihin Talib. "Industry 4.0: A Review on Industrial Automation and Robotic." Jurnal Teknologi, 2016.

Barcus, John. "Accelerating Innovation at the Speed of Industry 4.0." Manufacturing Leadership Council.

Batam, Infineon Technologies. Manager Communication Handbook: Leading and Managing People. Batam, 2019.

Benesova, Andrea, Martin Hirman, Frantisek Steiner, and Jiri Tupa. "Requirements for Education 4.0 and Study Programs within Industry 4.0." In Proceedings of the International Conference on Industrial Engineering and Operations Management, 2019.

Buntak, Krešimir, Matija Kovačić, and Ivana Martinčević. "Knowledge Management in Digital Era." In Conference: Advances in BusinessRelated Scientific Research Conference. Ljubljana, 2019.

Catlin, Tanguy, Jay Scanlan, and Paul Willmott. Raising Your Digital Quotient, 2015.

Dreyer, Wim A. "Being Church in the Era of 'Homo Digitalis." Verbum et Ecclesia (2019).

Flores, Emmanuel, Xun Xu, and Yuqian Lu. "Human Capital 4.0: A Workforce Competence Typology for Industry 4.0." Journal of 
Manufacturing Technology Management (2020).

Franklin, Kirk, and Nelus Niemandt. "Polycentrism in the Missio Dei." HTS

Teologiese Studies / Theological Studies (2016).

Gallardo-Echenique, Eliana, Janaina Oliveira, Luis Marqués Molías, and Francesc Esteve. "Digital Competence in the Knowledge Society." MERLOT Journal of Online Learning and Teaching (JOLT) 11, no. 1 (2018): 1-16.

Gilster, Paul. Digital Literacy. New York: Willey, 1997.

Hardani. Metoda Penelitian Kuantitatif Dan Kualitatif. Yogyakarta: Penerbit Pustaka Ilmu, 2020.

Harianto GP. Teologi Pastoral. Yogyakarta: Penerbit Andi, 2020.

Heriyanto, Djaman Sator, Aan Komariah, and Asep Suryana. "Character Education in the Era of Industrial Revolution 4.0 and Its Relevance to the High School Learning Transformation Process." Utopia y Praxis Latinoamericana (2019).

Indiastuti, Rina. "Pengembangan Ekosistem Inovasi Dan Kurikulum Edukasi Untuk Mendukung Revolusi Teknologi Manufaktur 4.0.” In Industrial Summit: Implementasi Industri 4.0 Dalam Rangka Transformasi Lanskap Industri Nasional Menuju Top 10 Ekonomi Dunia 2030. Jakarta: Direktorat Jenderal Pembelajaran dan Kemahasiswaan Kementerian Riset, Teknologi, dan Pendidikan Tinggi, 2018.

Ministry, Rehobot. "Kebenaran Yang Mentransformasi." Rehobot Ministry.

Mohebi, Laila. "Educational Leadership and Digital Culture." SSRN Electronic Journal (2019).

Nafea, Rania, and Esra Kilicarslan Toplu. "Future of Education in Industry 4.0: Educational Digitization - A Canadian Case Study." In Business Management and Communication Perspectives in Industry 4.0, 2020.

Purnomo, Aldrin, and Yudhy Sanjaya. "Tantangan Dan Strategi Gereja Menjalankan Misi Allah Dalam Menghadapi Penerapan Industri 4.0 Di Indonesia." Diegesis Jurnal Teologi Kharismatika 3, no. 2 (2020): 91106.

Rahmat, Pupu Saeful. "Penelitian Kualitatif." Journal Equilibrium, 2009.

Ridsdale, Chantel, James Rothwell, Mike Smit, Hossam Ali-Hassan, Michael Bliemel, Dean Irvine, Daniel Kelley, Stan Matwin, and Brad Wuetherick. "Strategies and Best Practices for Data Literacy Education." Knowledge Synthesis Report (2015).

Schmid, Katherine G. "Digital Inculturation." In Missio Dei in a Digital Age, edited by Jonas Kurlberg and Peter M. Phillips. London: SCM Press, 2020.

Smolnikova, Marketa. "Next Step: Data Literacy Measurement." Prague: University of Economics, W. Churchill Sq. 4, 2021.

Sudrajat, Didi. Metode Penelitian Pendidikan Dengan Pendekatan Kuantitaif. Solo: Indo Pustaka Sinergis, 2016.

Umachandran, Krishnan, Valentina Della Corte, P. Amuthalakshmi, Debra Ferdinand-James, Mohamed Mohamed Tolba Said, Barbara Sawicka, Giovana Del Gaudio, et al. "Designing Learning-Skills towards 
Industry 4.0." World Journal on Educational Technology: Current Issues (2019).

Widjaja, Fransiskus Irwan. Misiologi Antara Teori, Fakta Dan Pengalaman. 1st ed. Batam: Andi Offset Yogyakarta, 2018.

Widjaja, Fransiskus Irwan, Fredy Simanjuntak, and Noh Ibrahim Boiliu. "Repositioning Mission in Postmodern Culture." In Proceedings of the 1st International Conference on Education, Society, Economy,

Humanity and Environment (ICESHE 2019). Paris, France: Atlantis Press, 2020. https://www.atlantis-press.com/article/125936174.

Wongso, Peter. Theologia Penggembalaan. Malang: Literatur SAAT, 1983. 